\title{
AVALIAÇÃO DA QUALIDADE DA ÁGUA: DETERMINAÇÃO DOS POSSÍVEIS CONTAMINANTES DA ÁGUA DE POÇOS ARTESIANOS NA REGIÃO NOROESTE FLUMINENSE
}

\author{
Camila Vieira Goudinho VITÓ, Luma Janayna Bernardo Ferreira da SILVA, Karoline de Moura Lima \\ OLIVEIRA, Anders Teixeira GOMES* \& Camila Ramos de Oliveira NUNES
}

Instituto Federal de Educação, Ciências e Tecnologia Fluminense, campus Itaperuna, Itaperuna, RJ, Brasil.

*Autor para correspondência: anders.gomes@iff.edu.br

http://dx.doi.org/10.18571/acbm.111

\section{RESUMO}

A água é um recurso natural essencial para a vida na Terra. É considerado solvente universal pois consegue dissolver a maior parte das moléculas existentes. O Brasil é considerado uma das maiores reservas hídricas do mundo, porém, a água é um recurso limitado e com o passar dos anos vem se tornando mais escassa, resultado do uso irracional. Por ser de grande importância para o ser humano, ela precisa ser considerada potável para que possa ser consumida. O Conselho Nacional do Meio Ambiente (CONAMA) é o órgão responsável pela qualidade da água no Brasil. O consumo de águas subterrâneas é muitas vezes preferido por serem consideradas mais limpas quando comparadas às águas superficiais. Porém, dependendo do local onde o poço é perfurado, a água subterrânea pode acabar adquirindo contaminantes químicos e/ou biológicos originados de agrotóxicos, lixo, esgoto, dentre outros. No século XX, a região Noroeste Fluminense foi bastante utilizada para agricultura, com destaque para a produção de café. Atualmente, lavouras de café e tomate são predominante em algumas localidades. Os agrotóxicos utilizados nas plantações podem ser lixiviados pelo solo, contaminando a água dos lençóis freáticos. Nas zonas rurais, onde não se tem água encanada, é comum a utilização de poços rasos ou artesianos. Muitas vezes esses poços são perfurados perto dessas plantações, o que aumenta o risco de contaminação da água. Com o objetivo de verificar a qualidade da água de poços, muitas vezes destinados para o consumo, foram selecionados poços de áreas rurais da região Noroeste Fluminense para a realização de análises físico-química da água. Para determinação de íons possivelmente provenientes da contaminação por agrotóxicos, foi realizada análise em cromatógrafo de íons (IF Fluminense Polo de Inovação Campos dos Goytacazes). Os resultados obtidos foram confrontados com a legislação vigente para potabilidade.

Palavra-chave: Água, Contaminação, Agrotóxicos, Cromatografia de íons.

\begin{abstract}
Water is an essential natural resource for life on Earth. It is considered universal solvent because it can dissolve most of the existing molecules. Brazil is considered one of the largest water reserves in the world, but water is a limited resource and over the years it has become scarce as a result of irrational use. Because it is of great importance to the human being, it must be considered drinkable so that it can be consumed. The National Environment Council (CONAMA) is the body responsible for water quality in Brazil. Groundwater consumption is often preferred because it is considered cleaner compared to surface water. However, depending on where the well is drilled, groundwater may end up acquiring chemical and / or biological contaminants from pesticides, garbage, sewage, among others. In the twentieth century, the Northwest Fluminense region was widely used for agriculture, with emphasis on coffee production. Currently, coffee and tomato plantations are predominant in some localities. The pesticides used in the plantations can be
\end{abstract}


leached by the soil, contaminating the water from the groundwater. In rural areas, where there is no running water, it is common to use shallow or artesian wells. Often these wells are drilled near these plantations, which increases the risk of water contamination. In order to verify the water quality of wells, often destined for consumption, wells were selected from rural areas of the Northwest Fluminense region to perform physical-chemical analyzes of the water. For determination of ions possibly resulting from the contamination by pesticides, an ion chromatograph was analyzed (IF Fluminense Polo de Inovação Campos dos Goytacazes). The results obtained were confronted with the current legislation for potability.

Keywords: Water, Pollution, Pesticides, Ion Chromatography.

\section{Introdução}

\section{1 Água}

A água é considerada um recurso natural limitado e sua disponibilidade é cada vez menor (BARRETO; GARCIA, 2010). Ela é uma riqueza natural e é indispensável à vida na Terra.

Segundo Almeida (2010), o planeta é formado por aproximadamente 97,5\% de água salgada (mares e oceanos) e apenas $2,5 \%$ de água doce, esta que pode ser encontrada em geleiras, rios, águas subterrâneas e até mesmo na atmosfera.

Essa disponibilidade da água e a decorrência de estar presente nos 3 estados físicos (sólido, líquido e gasoso) simultaneamente faz com que ela tenha um ciclo natural. O ciclo hidrológico é vital e responsável pela renovação dessa importante molécula bioquímica.

Allègre et al., (1996) dizem que a água que sofre o processo de evaporação se torna mais purificada. Esta água límpida e gasosa, também conhecida por vapor de água, está presente na atmosfera. Este vapor de água condensa-se em gotículas que formam as nuvens. O vento carrega consigo essas nuvens, que por serem consideradas instáveis, desmontam-se e geram o que é chamado de chuva.

Uma vez na superfície terrestre a água perpassa pelo solo e circula através de linhas de água que se reúnem em córregos e rios até atingir os oceanos (escoamento superficial) ou se infiltra nos solos e nas rochas entre os poros, através dos seus poros, fissuras e fraturas (escoamento subterrâneo) (UFA; UFSC, 2009).

É necessário lembrar-se de algumas propriedades da água, as quais contribuem para tal importância à vida: ser o solvente universal, possuir um alto calor específico e apresentar capacidade térmica.

A água é considerada o solvente universal, pois consegue dissolver a maior parte das moléculas existentes. O seu alto calor específico faz com que sua evaporação seja mais lenta, evitando assim, a perda de muita água em ambientes secos e quentes. A água também é capaz de controlar o calor de outras superfícies sem alterar drasticamente a própria temperatura, prova disto são os oceanos e mares que controlam o calor do planeta e produz condições necessárias à vida na Biosfera.

O calor é armazenado pelos oceanos durante o verão e é libertado de volta para a atmosfera no inverno. Assim, os oceanos moderam o clima através da redução das diferenças de temperatura entre as estações do ano (GOMES; CLAVICO, 2005).

Marques et al. (2007) e Moreira et al. (2015) compartilham a ideia que durante as últimas décadas a preocupação com a qualidade e a disponibilidade da água para o consumo humano vem aumentando, pois, o rápido desenvolvimento industrial, o aumento da população e a produtividade agrícola vem ocasionando diversos impactos hidrológicos. É necessário que as águas subterrâneas sejam preservadas e utilizadas de forma consciente e sustentável o mais rápido possível. 
Embora dependa da água para sobrevivência, a sociedade polui e degrada este recurso, provocando perdas na quantidade e principalmente na qualidade da água. A preservação da qualidade da água é fundamental para o equilíbrio aquático e o abastecimento da população (SAIDELLES et al., 2014).

\title{
1.2 Águas subterrâneas
}

Iritani; Ezaki (2012) lembram que quando o assunto é água, o senso comum é pensar somente em águas superficiais, tais como rios, lagos, dentre outros, esquecendo-se de que há reservatórios subterrâneos por toda parte do planeta. Essas águas encontram-se em aquíferos, que são importantes reservatórios de águas doces no subsolo.

As águas subterrâneas tornam-se disponíveis ao uso humano principalmente a partir da perfuração de poços. Podem também aflorar na forma de fontes quando a superfície do terreno intercepta o lençol freático (NANES et al., 2012).

De acordo com Oliveira; Loureiro (1998), com o aumento da poluição antrópica em águas superficiais e o mau uso destas, a alternativa do século tem sido usufruir das águas subterrâneas. Essas águas são consideradas mais limpas, quando comparadas às águas superficiais, por não estarem tão propícias à poluição e por sofrerem processos de filtração no solo, o que torna a água um pouco mais purificada.

Cleary (2007) diz que mesmo em regiões onde as condições geológicas são favoráveis a grande parte de águas superficiais, como nas regiões Sul e Sudeste do país, corre o risco de escassez dessas águas, devido à grande quantidade de demanda em períodos de estiagem e secas.

\begin{abstract}
Os aquíferos são formações geológicas do subsolo, constituída por rochas permeáveis, seu abastecimento acontece por infiltração da água proveniente da superfície. Desta forma, a entrada de substâncias contaminantes pode ocorrer através da percolação no solo, tornando a água imprópria para o consumo. Problemas como esses podem ser evitados e remediados com o monitoramento do fluxo, da pluma de contaminantes (possíveis focos de contaminação) e precaução de possíveis contaminadores (SOUZA et al., 2012 a 2013).

Ao contrário das águas superficiais, uma vez ocorridas à poluição, as baixas velocidades de fluxo tendem a promover uma recuperação muito lenta da qualidade. Dependendo do tipo de contaminante, essa recuperação pode levar anos, com custos muito elevados, não raro, proibitivos. A poluição/contaminação da água subterrânea pode ser direta ou indireta. Ambas podem estar relacionadas com as atividades humanas e/ou por processos naturais. As fontes mais comuns de poluição e contaminação direta das águas subterrâneas são: deposição de resíduos sólidos no solo, esgotos e fossas, vazamento de substâncias tóxicas, atividades agrícolas e etc. (KETTELHUT et al. 2007).
\end{abstract}

\subsection{Possíveis contaminantes em águas subterrâneas}

A água subterrânea apresenta geralmente excelentes qualidades químicas e físicas, sendo assim apta para o consumo humano, muitas vezes sem necessidade de tratamento prévio. A contaminação ocorre quando alguma alteração na água coloca em risco a saúde ou o bem-estar de uma população (HIRATA, 2003).

Apesar da crença popular de que a água subterrânea está protegida contra as diversas formas de contaminação, os cientistas estão descobrindo poluição em aquíferos de todos os continentes, tanto nas proximidades de lavouras, quanto de fábricas e cidades (REBOUÇAS, 2003).

Basicamente, a contaminação em áreas rurais é originada por despejos de lixos inadequados e esgotos domésticos ao ambiente e a utilização de produtos agrotóxicos e pesticidas 
em áreas de cultivo. Esses produtos usados em plantações lançam ao solo íons que podem ser tóxicos.

O problema vem à tona quando a água entra em contato com esse solo. Por ser um excelente solvente, a água carregará consigo esses íons e os manterá dissolvidos. Quando alguém beber dessa água, consumirá também essas substâncias.

\subsection{Parâmetros físico-químicos para a qualidade da água}

Os parâmetros físico-químicos normalmente avaliados quando se trata de água para o consumo são: $\mathrm{pH}$, turbidez, condutividade e sólidos totais de acordo com a Resolução CONAMA $\mathrm{n}^{\circ} 357 / 2005$ e CONAMA n ${ }^{\circ} 396 / 2008$.

A condutividade elétrica da água indica a sua capacidade de transmitir a corrente elétrica em função da presença de substâncias dissolvidas, que se dissociam em ânions e cátions. Quanto maior a concentração iônica da solução, maior é a oportunidade para ação eletrolítica e, portanto, maior a capacidade em conduzir corrente elétrica (FUNASA, 2014). Ela expressa a interferência à passagem de luz através do líquido, portanto, de maneira simplificada, mede a transparência da água (UFA; UFSC, 2009).

As águas subterrâneas normalmente não apresentam problemas devido ao excesso de turbidez (CORCÓVIA; CELLIGOI, 2012).

O termo pH representa a concentração de íons hidrogênio em uma solução, o qual pode ser determinado através de aparelhos denominados de potenciômetros ou colorímetros (PALUDO, 2010). Segundo FELTRE (2004), o pH indica se o meio está ácido ( $\mathrm{pH}<7$ ), alcalino (pH > 7) ou neutro $(\mathrm{pH}=7)$. Cada meio tem seu próprio valor de $\mathrm{pH}$. $\mathrm{O} \mathrm{pH}$ de águas subterrâneas varia entre 5,5 a 8,5 .

A condutividade refere-se à capacidade que a água tem de transmitir corrente elétrica devido aos íons, cátions (cargas positivas) e aos ânions (cargas negativas), presentes nela a partir da dissociação de outras substâncias. (NA - Agência Nacional de Águas).

Sólidos totais dissolvidos é o conjunto de todas as substâncias orgânicas e inorgânicas contidas num líquido sob formas moleculares ionizadas ou microgranulares. (ARAÚJO; SANTOS; OLIVEIRA, 2012/2013). A entrada de sólidos na água pode ocorrer de forma natural (processos erosivos, organismos e detritos orgânicos) ou antropogênica (lançamento de lixo e esgotos) (UFA, UFSC, 2009).

\subsection{Aspectos legais relacionados à água}

A Resolução $\mathrm{n}^{\circ}$ 357, de dezessete de março de 2005, do Conselho Nacional do Meio Ambiente (CONAMA), dispõe sobre a classificação os corpos de água e diretrizes ambientais para o seu enquadramento, bem como estabelece as condições e padrões de lançamento de efluentes.

A Resolução CONAMA n ${ }^{\circ}$ 396, de três de abril de 2008, dispõe sobre a classificação e diretrizes ambientais para o enquadramento das águas subterrâneas e das outras providências, completando a prevenção e controle da poluição da água subterrânea, sendo essa a mais recente. (BRASIL, 2008).

Segundo Nascimento et al., (2009), as leis citadas restringem o uso sem controle da água subterrânea por meio de instrumentos que visam conservar os mananciais subterrâneos a fim de promover a redução das alterações e dos impactos causados aos aquíferos que são vulneráveis a contaminantes que apresentam características persistentes e móveis.

Fazendo-se necessária a aplicação destas e a efetiva fiscalização para que as políticas públicas de proteção da quantidade e da qualidade da água subterrânea de forma ampliada possam, de fato, corroborar para a manutenção da qualidade da mesma, inclusive para fins de consumo humano, se for o caso (SANTOS, 2014). 
Os órgãos ambientais, em conjunto com os órgãos gestores dos recursos hídricos e da saúde, deverão promover a implementação de Áreas de Restrição e Controle do Uso da Água Subterrânea em caráter excepcional e temporário, quando, em função da condição da qualidade e quantidade da água subterrânea, houver a necessidade de restringir o uso ou a captação da água para proteção dos aquíferos, da saúde humana e dos ecossistemas (CONAMA, 2008).

A Resolução CONAMA n 396/2008 ainda estabelece em seu Art. 12, que os parâmetros a serem selecionados para subsidiar a proposta de enquadramento das águas subterrâneas em classes deverão ser escolhidos em função dos usos preponderantes, das características hidrogeológicas, hidrogeoquímicas, das fontes de poluição e entre outros critérios técnicos definidos pelo órgão competente. Dentro desses parâmetros selecionados, deverão ser considerados, no mínimo, Sólidos Totais Dissolvidos, nitrato e coliformes termotolerantes.

A Resolução n³57/2005 estabelece no Art. 14, as condições e padrões.

Tabela 1: Padrões estabelecidos na resolução n ${ }^{\circ} 357$ do CONAMA.

\begin{tabular}{l|c}
\hline \multicolumn{1}{c|}{ Parâmetros } & Limites Permitidos \\
\hline $\mathrm{pH}$ & 6,0 a 9,0 \\
\hline Turbidez $(\mathrm{UNT})$ & $40 \mathrm{UNT}$ \\
\hline Cloreto $\left(\mathrm{Cl}^{-}\right)$ & $250 \mathrm{mg} / \mathrm{L}$ \\
\hline Fluoreto $\left(\mathrm{F}^{-}\right)$ & $1,4 \mathrm{mg} / \mathrm{L}$ \\
\hline Nitrato $\left(\mathrm{NO}_{3}^{-}\right)$ & $10,0 \mathrm{mg} / \mathrm{L}$ \\
\hline Nitrito $\left(\mathrm{NO}_{2}^{-}\right)$ & $1,0 \mathrm{mg} / \mathrm{L}$ \\
\hline Sulfato $\left(\mathrm{SO}_{4}{ }^{2-}\right)$ & $250 \mathrm{mg} / \mathrm{L}$ \\
\hline Fosfato $\left(\mathrm{PO}_{4}{ }^{3-}\right)$ & - \\
\hline Brometo $\left(\mathrm{Br}^{-}\right)$ & - \\
\hline Fonte: Dados da pesquisa. &
\end{tabular}

A Portaria n ${ }^{\circ}$ 2.914, de 12 de dezembro de 2011 do Ministério da Saúde, dispõe-se à água destinada ao consumo humano proveniente de sistema e solução alternativa de abastecimento de água. No Art. $5^{\circ}$ estabelece que a água para consumo humano tenha que ser potável destinada à ingestão, preparação e produção de alimentos e à higiene pessoal, independentemente da sua origem. No mesmo a água potável é a água que atende ao padrão de potabilidade estabelecido nesta Portaria e que não ofereça riscos à saúde.

Nesta Portaria fica claro que, para parâmetros físico-químicos, é necessário considerar o histórico de resultados para avaliar se a água está atendendo ou não os padrões estabelecidos pela mesma. Antes, qualquer resultado unitário fora dos padrões já podia classificar a potabilidade da água.

Houve uma redução do limite permitido para a turbidez após a filtração, de 1,0 para 0,5 NTU. Foram inseridos 19 novos ensaios de parâmetros para monitoramento, a maioria deles para compostos orgânicos e agrotóxicos (Revista DAE, 2012).

Esta pesquisa teve como objetivos: (1) avaliar a qualidade da água de poços artesianos e rasos da Região Noroeste Fluminense por meio de análises físico-químicas, e cromatografia iônica para analisar possíveis íons presentes na amostra; (2) comparar os resultados obtidos da qualidade da água subterrânea com os parâmetros estabelecidos pelas Portarias n ${ }^{\circ}$. 2.914, de 12/12/2011, do Ministério da Saúde, Resolução CONAMA n ${ }^{\circ}$ 357, de 17/03/2005 e Resolução CONAMA n ${ }^{\circ}$. 396, de 03/04/2008.

\section{Materiais e Métodos}

A pesquisa teve início no mês de junho de 2016 e estendeu-se até a primeira quinzena do mês de outubro, período no qual foram realizadas as coletas e as análises. Realizou-se as análises 


\section{ACTA \\ Biomedica Brasiliensia}

ISSN: 2236-0867

no Polo de Inovação Campos dos Goytacazes localizado no IF Fluminense Polo de Inovação Campos dos Goytacazes, que é uma unidade composta por vários laboratórios onde foram feitas as análises físico-químicas e cromatográficas.

Efetuou-se a avaliação de quatro poços artesianos na área rural e um poço artesiano na área urbana na Região Noroeste Fluminense, totalizando-se cinco localidades distintas. Coletou-se em cada poço uma amostra para a realização das análises. A coleta das amostras foi programada para o período da manhã, quando a temperatura do ar é mais baixa e há menor probabilidade de distorção dos resultados.

Fez-se as coletas das amostras para análise físico-química e cromatográfica, com o auxílio de uma garrafa PET contendo água mineral com gás, pois não possuíamos vidrarias esterilizadas e apropriadas para a coleta. Com o isso a garrafa com água mineral teoricamente já é esterilizada (Figura 1).

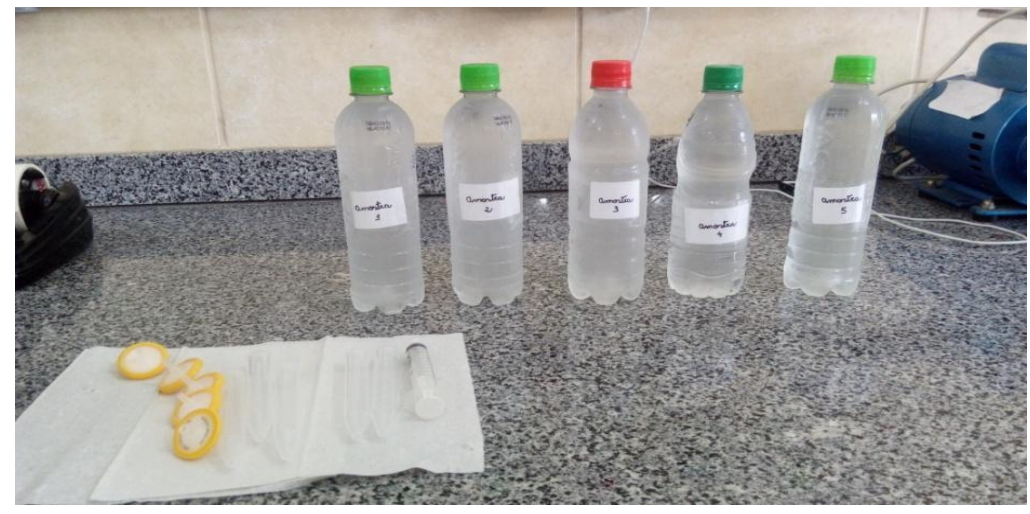

Figura 1: Materiais Utilizados para realização das análises cromatográficas. Fonte: Arquivo dos autores

A garrafa foi somente aberta na hora da coleta, onde fez-se a lavagem química da mesma, três vezes com a amostra a ser coletada, fazendo assim a ambientação do frasco de coleta. As amostras foram coletadas junto à torneira acoplada a cada poço. Abriu-se a torneira e deixou-se a água fluir por alguns segundos, para assim limpar a tubulação. Após este tempo, reduziu-se o fluxo para a amostra coletada não respingar fora do frasco de coleta.

Após coleta, evitou-se qualquer tipo de contato com o recipiente para que não houvesse contaminação. As amostras foram mantidas sob refrigeração até o momento das análises.

Para análises físico-químicas, determinou-se $\mathrm{pH}$, turbidez, sólidos totais e condutividade. Utilizou-se uma sonda multiparâmetros da marca Hanna Instruments Modelo HI 9829 para determinar $\mathrm{pH}$, condutividade e sólidos totais. Usou-se um béquer de $100 \mathrm{~mL}$ para cada amostra, totalizando-se cinco béqueres, onde fez-se a lavagem química de cada um e em seguida encheu-se cada um deles. A sonda foi submersa em cada béquer contendo a amostra para leitura dos parâmetros. Antes de analisar a próxima amostra, a sonda era submetida à uma lavagem com água destilada.

Para medir a turbidez utilizou-se o turbidímetro da marca MS TECNOPON@ (Figura 2), instrumentação, que foi previamente calibrado. Cada amostra foi posta em um frasco próprio para análise que foi inserido no aparelho medindo-se assim a turbidez. Ao trocar de amostra o frasco era submetido à lavagem química com a próxima amostra a ser medida. 


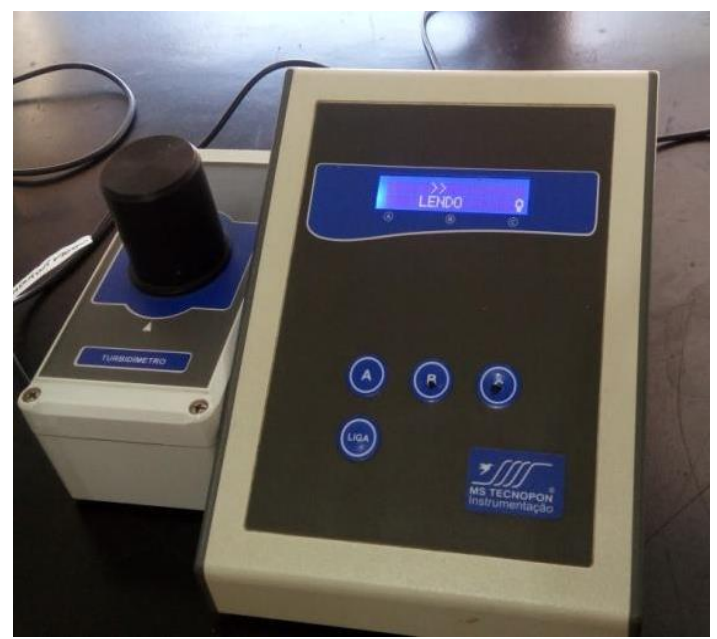

Figura 2: Turbidímetro. Fonte: Arquivo dos autores.

Para realização da análise cromatográfica, fez-se necessário o preparo prévio das amostras de águas de poços. Coletou-se, com uma seringa plástica AdvantiVe ${ }^{\circledR}$ de $10 \mathrm{~mL}$, uma amostra de cada garrafa de água, para a filtração das amostras utilizando-se filtros Millipori Mille - GV Hydrophilic PVDF 0,22 $\mu \mathrm{m}$. Cada amostra requereu o uso de um filtro. Depois de filtrada, as amostras de água foram transferidas para um vial de plástico de $11 \mathrm{~cm}$ com tampa, sendo ao total cinco vials.

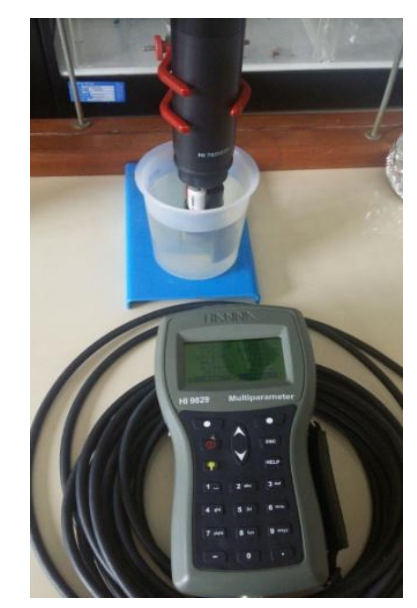

Figura 3: Sonda multiparâmetros. Fonte: Arquivos dos autores.

A análise cromatográfica foi realizada em um cromatógrafo de íons 883 Basic IC Plus Metrohm (Figura 4) calibrado para detectar e quantificar os íons Brometo ( $\left.\mathrm{Br}^{-}\right)$, Cloreto $\left(\mathrm{Cl}^{-}\right)$, Fluoreto $\left(\mathrm{F}^{-}\right)$, Fosfato $\left(\mathrm{PO}_{4}^{-}\right)$, Nitrato $\left(\mathrm{NO}_{3}{ }^{-}\right)$, Nitrito $\left(\mathrm{NO}_{2}^{-}\right)$e Sulfato $\left(\mathrm{SO}_{4}^{-}\right)$. A fase móvel utilizada foi Carbonato de Sódio/ Bicarbonato de Sódio. 


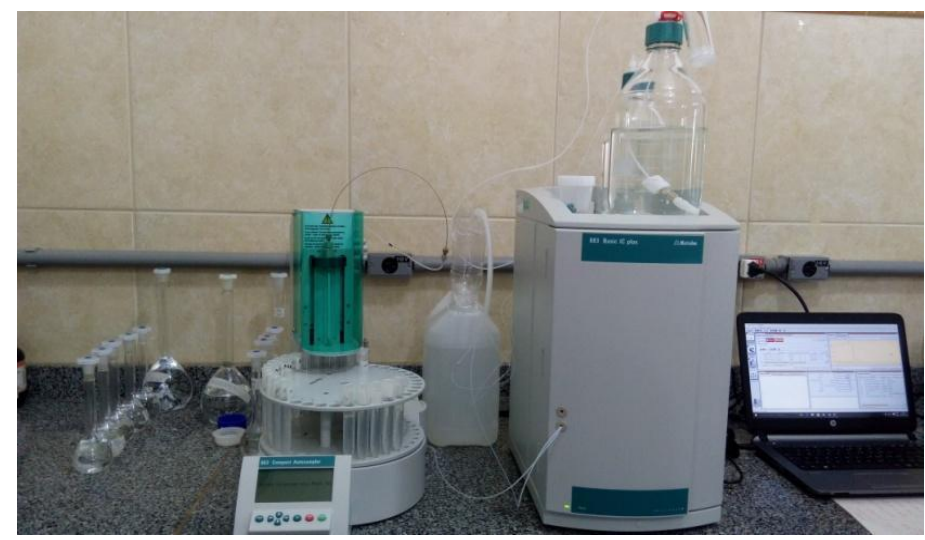

Figura 4: Cromatógrafo de Íons 883 Basic IC Plus Metrohm. Fonte: Arquivo dos autores.

Realizou-se o preparo de dois litros eluente para ânions (Metrosep A Supp 5), pesando-se 0,678 g de carbonato de sódio e 0,168 g de bicarbonato de sódio. Dissolveu-se ambos em cerca de $100 \mathrm{~mL}$ de água ultrapura. Transferiu-se a solução para um mesmo balão volumétrico de $2 \mathrm{~L} \mathrm{e}$ avolumou-se com água ultrapura. A concentração final da solução será 3,2 $\mathrm{mmol} / \mathrm{L}$ de carbonato de sódio e 1,0 $\mathrm{mmol} / \mathrm{L}$ de bicarbonato de sódio.

\section{Resultados e Discussão}

Os poços analisados foram identificados como A1, A2, A3, A4 e A5, sendo: amostra 1 Bica localizada na estrada BR RJ 220, próximo a Natividade - área rural (Figura 1); amostra 2 Poço do Instituto Federal Fluminense (IFF) campus Itaperuna - área urbana (Figura 2); amostra 3 - Poço localizado em Comendador Venâncio, distrito de Itaperuna - área rural (Figura 3); amostra 4 - Poço localizado no sítio Braúna, distrito de Bom Jesus do Itabapoana - área rural (Figura 4); amostra 5 - Poço localizado no distrito São Pedro do Paraíso - área rural (Figuras 5).

A escolha desses poços foi feita aleatoriamente tendo em vista a facilidade de captação da água e pela distribuição em diferentes localidades da região Noroeste Fluminense.

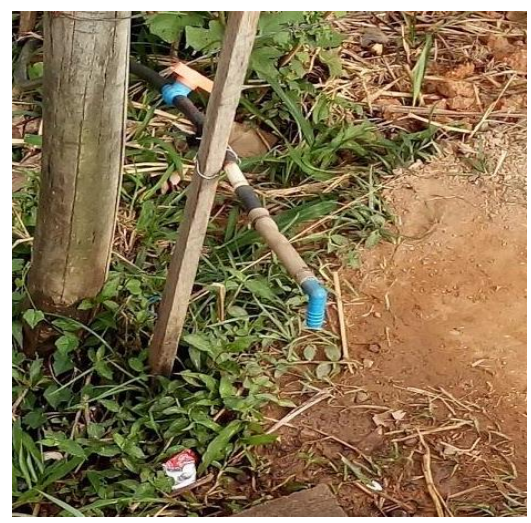

Figura 5: Visualização do poço amostra 1. Fonte: Arquivo dos autores.

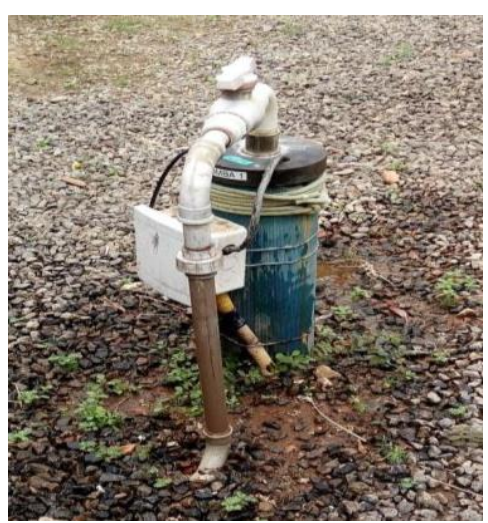

Figura 6: Visualização do poço amostra 2 Fonte: Arquivo dos autores. 


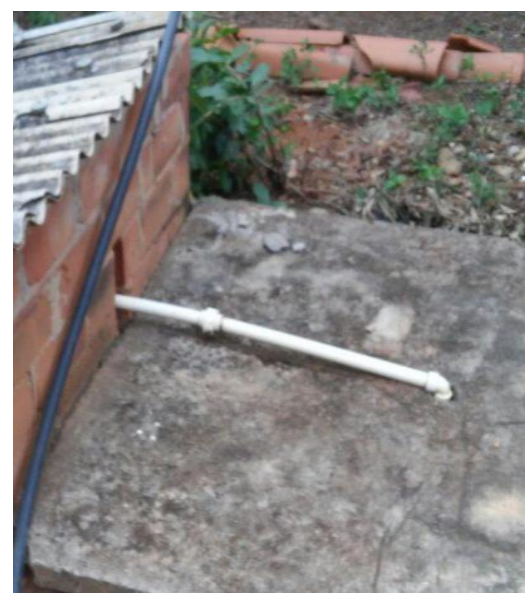

Figura 7: Visualização do poço amostra 3. Fonte: Arquivo dos autores.

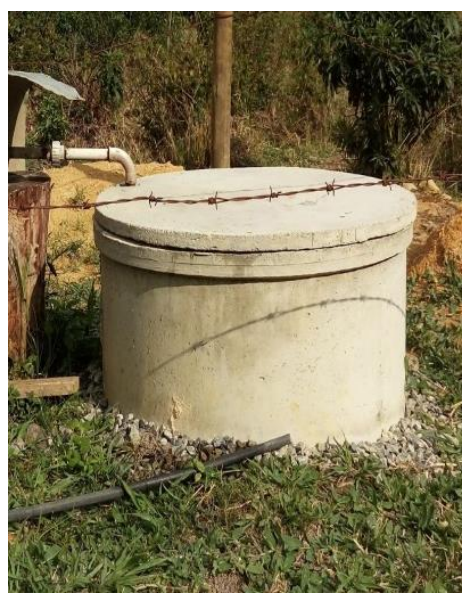

Figura 8: Visualização do poço amostra 4. Fonte: Arquivo dos autores.

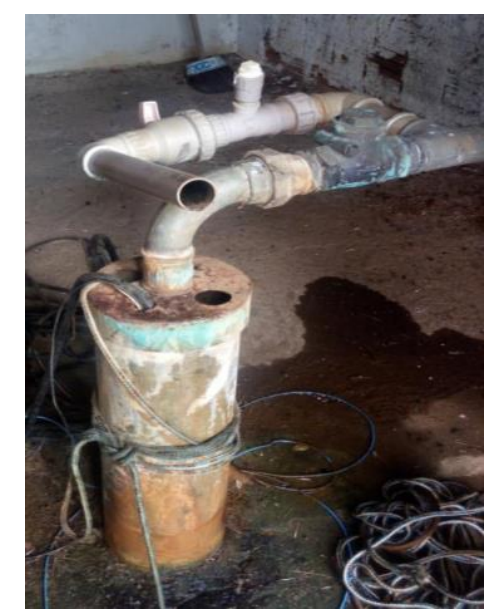

Figura 9: Visualização do poço amostra 5.

Fonte: Arquivo dos autores

\subsection{Análises Físico-Químicas}

Os resultados das análises físico-químicas das amostras coletadas no mês de outubro podem ser observados na tabela 2 .

Tabela 2. Resultados das análises físico-químicas das amostras de poços artesianos e rasos

\begin{tabular}{ccccc}
\hline Amostras & $\mathbf{p H}$ & $\begin{array}{c}\text { Condutividade Elétrica } \\
\left(\boldsymbol{\mu m} \mathbf{~ c m}^{-\mathbf{1}}\right)\end{array}$ & $\begin{array}{c}\text { Sólidos Totais } \\
\left(\mathbf{m g} . \mathbf{L}^{-\mathbf{1}}\right)\end{array}$ & Turbidez (NTU)* $^{*}$ \\
\hline Amostra 1 & 6.06 & 92 & 46 & 0,10 \\
\hline Amostra 2 & 6,74 & 616 & 308 & 0,16 \\
\hline Amostra 3 & 6,58 & 277 & 138 & 0,43 \\
\hline Amostra 4 & 6,76 & 141 & 71 & 0,80 \\
\hline Amostra 5 & 7,12 & 497 & 248 & 2,4
\end{tabular}

Fonte: Arquivo dos autores * Unidades Nefelométrica de Turbidez 


\section{$3.1 .1 \mathrm{pH}$}

Analisando os valores da tabela 2, pode-se observar que a amostra 1 apresenta o menor valor de $\mathrm{pH}(6,06)$ e a amostra 5, o maior valor de $\mathrm{pH}(7,12)$. A portaria $\mathrm{n}^{\mathrm{o}} 2.914$, de 12 de dezembro de 2011, do Ministério da Saúde recomenda que o $\mathrm{pH}$ da água varie entre os limites de 6,0 a 9,5, no entanto, a resolução $\mathrm{n}^{\circ} 357$, de 17 de março de 2005, decretada pelo Conselho Nacional do Meio Ambiente (CONAMA) recomenda que o $\mathrm{pH}$ de águas doces encontram-se entre 6,0 e 9,0. Sendo assim, nossas amostras apresentam valores de $\mathrm{pH}$ dentro do permitido pelas duas legislações.

\subsubsection{Sólidos Totais}

A entrada de sólidos na água pode ocorrer de forma natural (processos erosivos, organismos e detritos orgânicos) ou antropogênica (lançamento de lixo e esgotos) (UFA; UFSC, 2009).

A determinação dos níveis de concentração das diversas frações de sólidos é utilizada nos estudos de controle de poluição das águas naturais, caracterização de esgotos sanitários e de efluentes industriais e no controle de sistemas de tratamento de esgotos, resultando assim em um quadro geral da distribuição das partículas com relação ao tamanho e com relação à natureza química (TRENTIN; BOSTELMANN, 2010).

Os sólidos agem de maneira indireta sobre a vida aquática, impedem a penetração da luz, induzem o aquecimento da água o que, consequentemente, diminui a quantidade de oxigênio dissolvido no meio (LOUGON, 2009).

A qualidade da água que é direcionada para o abastecimento, os altos teores de sais minerais, tais como sulfato e cloreto, é associada à tendência de corrosão nos sistemas de distribuição, além de conferir sabor para a água. De acordo com o CONAMA (BRASIL, 2009), a concentração de sólidos dissolvidos deve ser menor que $500 \mathrm{mg} / \mathrm{L}$ em água para abastecimento público, das classes 1, 2 e 3. Já para as águas subterrâneas das classes 1 e 2, $1000 \mathrm{mg} / \mathrm{L}$.

\subsubsection{Condutividade elétrica}

A condutividade elétrica mede a capacidade que a água tem de transmitir correntes elétricas e está diretamente relacionada à concentração de espécies iônicas dissolvidas, principalmente inorgânicas (ANA - Agência Nacional de Águas).

\footnotetext{
Quanto maior a concentração iônica da solução, maior é a oportunidade para ação eletrolítica e, portanto, maior a capacidade em conduzir correntes elétricas. Muito embora não se possa esperar uma relação direta entre condutividade e concentração de sólidos totais dissolvidos, já que as águas naturais não são soluções simples, tal correlação é possível para águas de determinadas regiões onde exista a predominância bem definida de um determinado íon em solução (FUNASA, 2014).
}

Normalmente, a condutividade elétrica de águas naturais é inferior a $500 \mu \mathrm{S} / \mathrm{cm}$, sendo que valores superiores a estes podem indicar problemas de poluição (ANA - Agência Nacional de Águas).

\subsubsection{Turbidez}

A turbidez indica a presença de sólidos suspensos na água, que atuam diminuindo a sua transparência (PALUDO, 2010). 


\section{Biomedica Brasiliensia}

ISSN: 2236-0867

Observando a tabela 2, pode-se notar que as amostras 1,2, 3 e 4 apresentam um baixo valor de turbidez, diferentemente da amostra 5, a qual possui um valor mais alto (2,4 NTU). Essa discordância de valores pode ser explicada pela composição química que cada água possui em particular. Quando se coletou a amostra 5, observou-se um forte odor e cor de ferrugem vindo desta água, o que pode ser devido a alta presença de ferro nesta amostra.

Em alguns casos, águas ricas em íons $\mathrm{Fe}^{3+}$, podem apresentar uma elevação de sua turbidez quando entram em contato com o oxigênio do ar (CORCÓVIA; CELLIGOI, 2012). O contato imediato do íon ferro $(\mathrm{Fe})$ com o oxigênio $(\mathrm{O})$ da atmosfera ocasiona em uma reação química e o íon ferro transforma-se em óxido de ferro $\left(\mathrm{Fe}_{2} \mathrm{O}_{3}\right)$, também chamado de ferrugem, substância esta que é responsável pela coloração amarronzada dos materiais enferrujados.

Embora a amostra 5 possua um valor bem diferente dos outros quatro resultados, pode-se dizer que todas as cinco amostras coletadas estão dentro dos parâmetros da resolução $\mathrm{n}^{\circ} 357$, de 17 de março de 2005, decretada pelo Conselho Nacional do Meio Ambiente (CONAMA), que dita que as turbidezes de águas subterrâneas devem apresentar até 40 NTU.

\subsection{Análises cromatográficas}

As amostras tiveram o teor de íons brometo $\left(\mathrm{Br}^{-}\right)$, cloreto $\left(\mathrm{Cl}^{-}\right)$, fluoreto $\left(\mathrm{F}^{-}\right)$, fosfato $\left(\mathrm{PO}_{4}{ }^{3}\right)$, nitrato $\left(\mathrm{NO}_{3}{ }^{-}\right)$, nitrito $\left(\mathrm{NO}_{2}{ }^{-}\right)$e sulfato $\left(\mathrm{SO}_{4}{ }^{2-}\right)$ medidos por meio da cromatografia de íons. Para todos os íons avaliados foram construídas curvas analíticas, apresentadas no Anexo 1, o que permitiu a quantificação dos mesmos.

Os cromatogramas obtidos para cada amostra são apresentados nas figuras 10, 11, 12, 13 e 14.

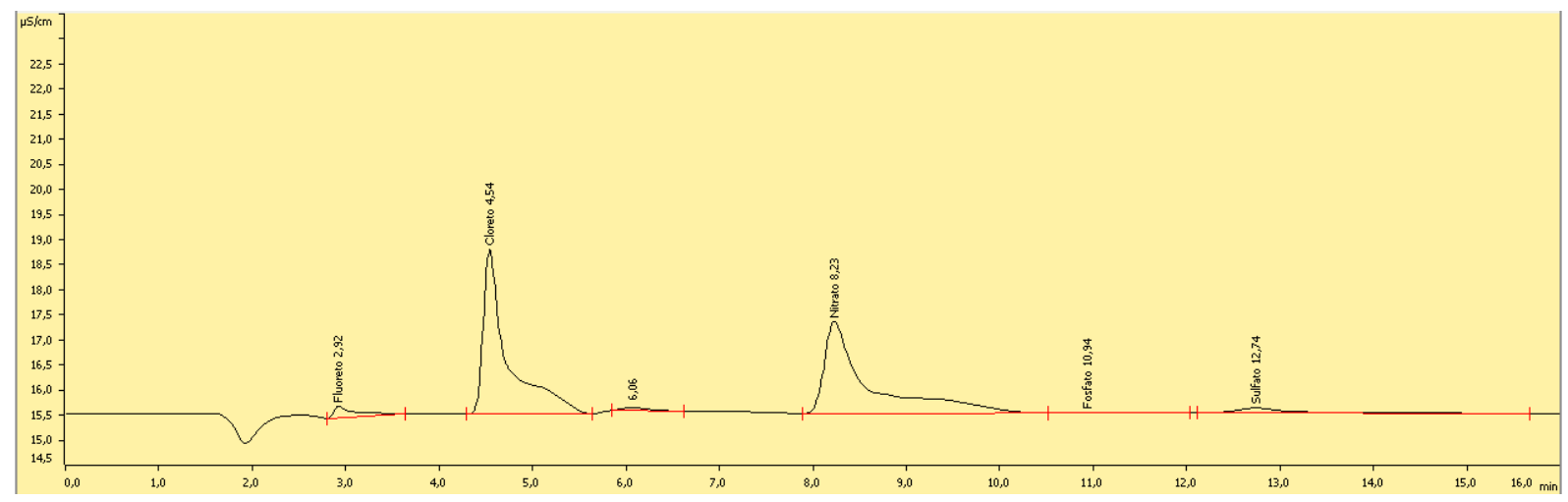

Figura 10. Cromatograma para a amostra 1. Fonte: Dados da pesquisa.

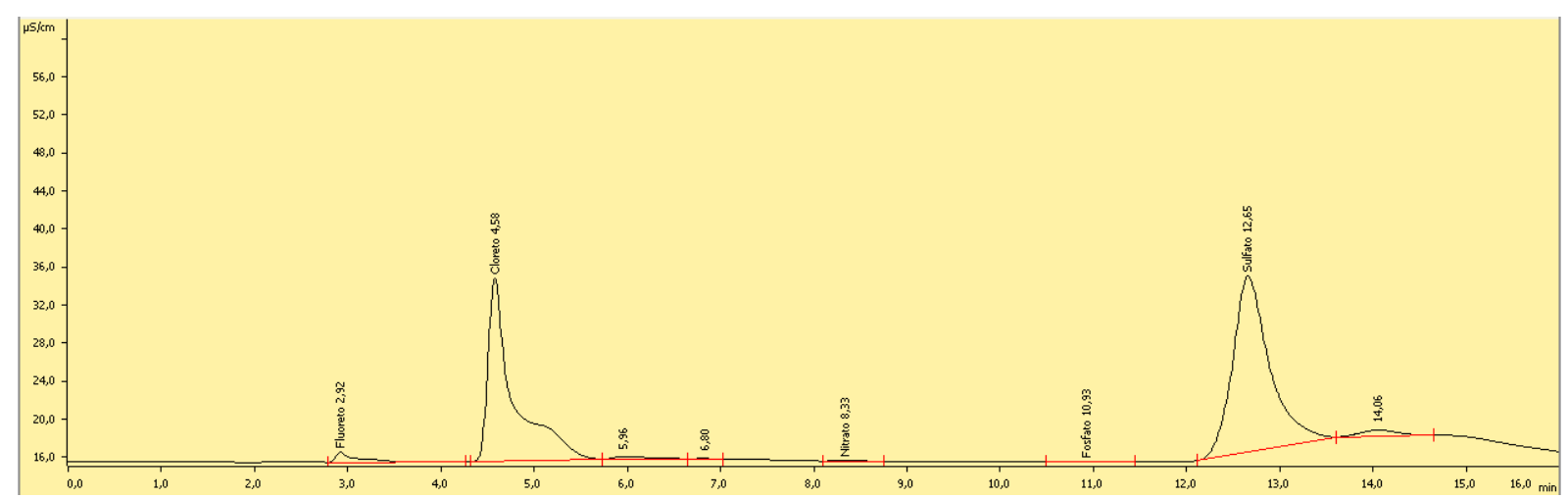

Figura 11. Cromatograma para a amostra 2. Fonte: Dados da pesquisa. 


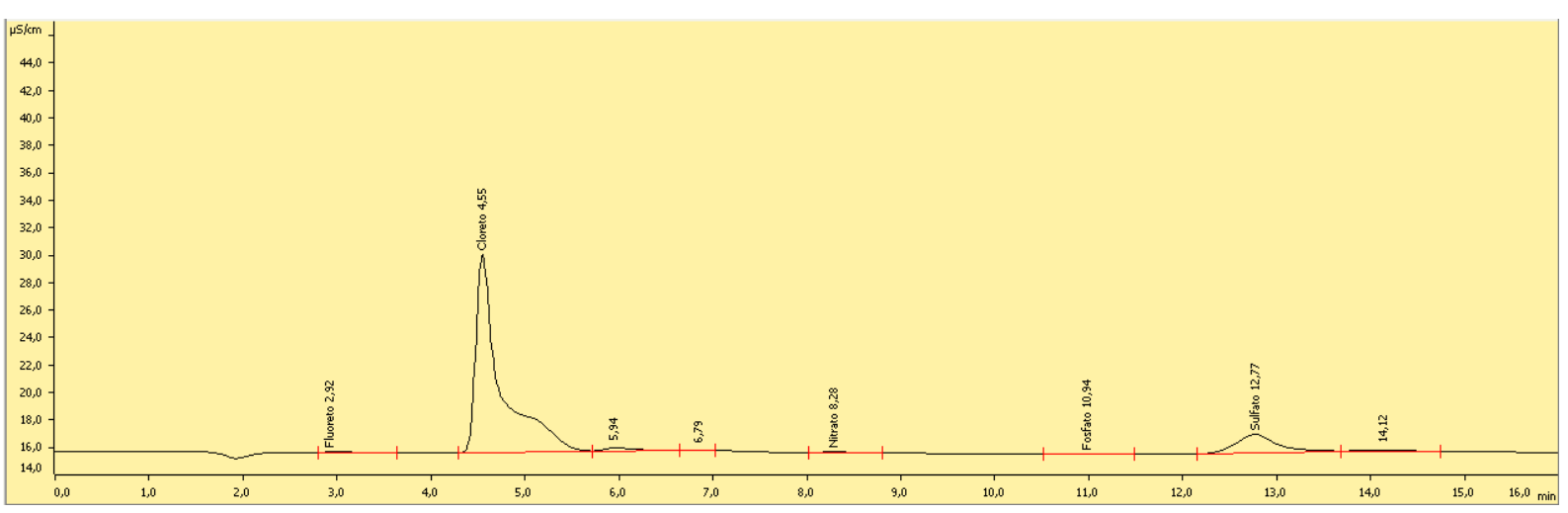

Figura 12. Cromatograma para a amostra 3. Dados da pesquisa.

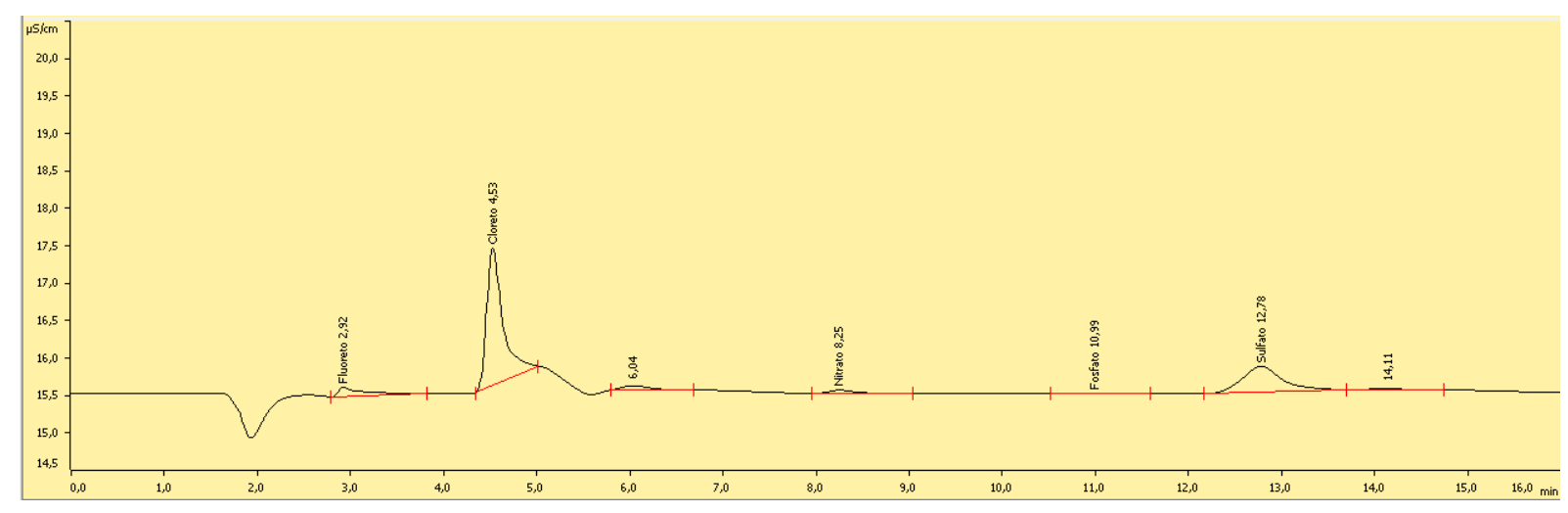

Figura 13. Cromatograma para a amostra 4. Fonte: Dados da pesquisa.

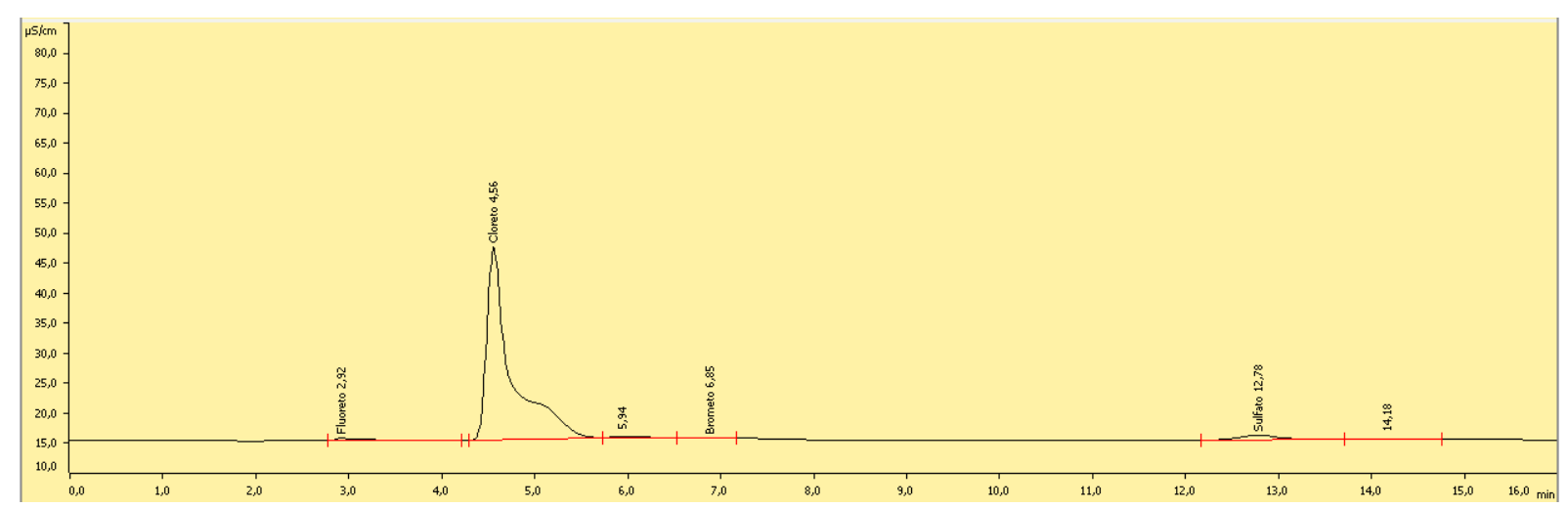

Figura 14. Cromatograma para a amostra 5. Fonte: Dados da pesquisa.

As amostras 1, 2, 3 e 5 precisaram ser diluídas, pois apresentaram alguns íons acima do ponto máximo da curva analítica. Os resultados de concentração dos íons em cada amostra são apresentados na Tabela 3. 
Tabela 3. Concentração (mg. $\left.\mathrm{L}^{-1}\right)$ dos íons avaliados em cada amostra de água

\begin{tabular}{|c|c|c|c|c|c|c|c|}
\hline \multirow[t]{2}{*}{ Amostras } & \multicolumn{7}{|c|}{ Concentração dos íons avaliados $\left(\mathrm{mg} \mathrm{L}^{-1}\right)$} \\
\hline & $\mathbf{F}^{-}$ & $\mathrm{Cl}^{-}$ & $\mathrm{NO}_{2}^{-}$ & $\mathrm{Br}^{-}$ & $\mathrm{NO}_{3}^{-}$ & $\mathrm{PO}_{4}{ }^{3-}$ & $\mathrm{SO}_{4}{ }^{2-}$ \\
\hline A1 & 0,231 & 9,530 & $<\mathrm{LD}$ & $<\mathrm{LD}$ & 22,027 & 0,368 & 1,089 \\
\hline A2 & 1,025 & 58,790 & $<\mathrm{LD}$ & $<\mathrm{LD}$ & 0,482 & 0,053 & 107,777 \\
\hline A3 & 0,167 & 37,809 & $<\mathrm{LD}$ & $<\mathrm{LD}$ & 0,840 & $<\mathrm{LD}$ & 8,462 \\
\hline A4 & 0,147 & 3,500 & $<\mathrm{LD}$ & $<\mathrm{LD}$ & 0,240 & $<\mathrm{LD}$ & 2,191 \\
\hline A5 & 0,427 & 87,953 & $<\mathrm{LD}$ & 0,173 & $<\mathrm{LD}$ & $<\mathrm{LD}$ & 5,168 \\
\hline
\end{tabular}

Fonte: Dados da pesquisa.

No século XX, a Região Noroeste Fluminense foi uma região de grande destaque agrícola, onde possuía grandes lavouras de café. Atualmente, esta região não é mais considerada destaque na agricultura, porém ainda é possível encontrar algumas plantações de café e tomate. Vale destacar que a região não possui tratamento de efluentes líquidos (estação de tratamento de esgoto), nem tampouco de resíduos sólidos, como aterros sanitários, de forma que o condicionamento de rejeitos sólidos ainda é feito na forma de "lixões" a céu aberto, podendo assim causar contaminações aos lençóis freáticos, como por exemplo, através de possíveis vazamentos do líquido gerado na decomposição dos resíduos orgânicos (popularmente conhecido como "chorume") para o reservatório de água subterrânea.

A falta de rede coletora de esgotos leva a população a adotar o uso de fossas ou sumidouros. O destino inadequado do esgoto doméstico e industrial acarreta a degradação do manancial subterrâneo pela lixiviação de contaminantes orgânicos e inorgânicos. Grande parte desses contaminantes chega ao lençol freático raso, podendo alcançar também o lençol freático profundo ou artesiano (BARBOSA, 2005).

Como por exemplo, nas lavouras café e tomate os agrotóxicos utilizados nas plantações podem ser lixiviados pelo solo, contaminando a água dos lençóis freáticos.

Procuraram-se poços de áreas rurais, uma vez que nestes locais não são comuns encontrar água encanada e com isso a utilização de poços artesianos é frequente. Portanto analisou-se a água desses reservatórios e comparou-se com a legislação e normas vigentes. Foram selecionados cinco poços artesianos da região que foram identificados como A1, A2, A3, A4 e A5. Nas análises, somente a amostra do corpo d'água A4 não precisou ser diluída, enquanto a A1, A2, A3 e A5 foram diluídas para que a concentração dos íons selecionados estivesse dentro do limite de detecção.

Os resultados foram satisfatórios para as amostras A2, A3, A4 e A5, pois elas possuíam concentrações dos íons dentro dos limites permitidos pelas as normas e legislação vigente. Somente a amostra A1 apresentou concentração do íon $\mathrm{NO}_{3}{ }^{-}$acima do permitido pela Resolução $\mathrm{n}^{\circ} 357$ do CONAMA.

Baird e Cann (2011) constataram aplicação de fertilizantes com nitrogênio, bem como inorgânicos e orgânicos, em plantações; cultivo do solo; fossas sépticas, esgoto humano depositado em sistemas sépticos e deposição atmosférica, decorrem a presença de nitrato nas águas subterrâneas. Com isso podemos relacionar que a amostra A1, encontra-se em área rural e o íon nitrato tem como uma de suas origens o uso de fertilizantes.

Os íons escolhidos para a análise descrita no presente trabalho obedeceram ao critério de serem possíveis contaminantes de corpos d'água através da atividade humana, como por exemplo, o uso de agrotóxicos e pesticidas nas plantações. 
O nitrito e o nitrato são encontrados de forma natural na água e no solo em baixas concentrações. A deposição de material orgânico no solo aumenta drasticamente a quantidade de nitrogênio. Esse nitrogênio é bioquimicamente transformado e por fim se transforma em nitrato que possui grande mobilidade no solo alcançando o manancial subterrâneo e ali se depositando (CAMPOS; ROHLFS, 2011).

Os fluoretos são compostos químicos formados pela combinação com outros elementos, encontrados em toda parte: solo, ar, água, nas plantas e na vida animal. Isto explica porque muitos alimentos contêm flúor. Ainda assim, a quantidade que ingerimos não passa de, em média, 0,3 mg de flúor por dia. O conteúdo de flúor na superfície terrestre varia de 20-500 ppm, aumentando nas camadas mais profundas, podendo chegar a 8.300 ppm, conferindo uma maior concentração de flúor às águas subterrâneas. Sua importância no solo se dá ao fato da incorporação deste elemento aos alimentos, principalmente nas folhas de chá, inhame e mandioca. Os fertilizantes contendo flúor, em teores que variam de 0,58 a $2,43 \%$, aparentemente não influenciam em sua concentração nos vegetais cultivados em solos fertilizados, embora a literatura relate mudanças abruptas na concentração de flúor em vegetais (FUNASA, 2014).

Os cloretos, geralmente, provêm da dissolução de minerais ou da intrusão de águas do mar, e ainda podem advir dos esgotos domésticos ou industriais. Em altas concentrações, conferem sabor salgado à água ou propriedades laxativas (FUNASA, 2014).

\section{Considerações Finais}

Através dos dados desta pesquisa foi possível verificar se as amostras de água dos cinco poços da região Noroeste Fluminense estavam dentro dos parâmetros das Portarias $n^{\circ} .2 .914$, de 12/12/2011, do Ministério da Saúde, Resolução CONAMA n ${ }^{\circ}$ 357, de 17/03/2005 e Resolução CONAMA $n^{\circ}$. 396, de 03/04/2008. Para os cinco pontos de coletas de água subterrânea, os resultados das análises físico-químicas foram satisfatórios, ou seja, os cinco poços (A1, A2, A3, A4 e A5) atenderam os critérios dos parâmetros estabelecidos pelas normas previamente relatadas.

O objetivo primordial não foi o de concluir se as amostras de águas de poços coletadas e analisadas poderiam ou não ser consumidas, neste caso seria necessário a realização de outros tipos de análises as quais elas não foram submetidas.

Com os resultados obtidos pelas análises cromatográficas permite-se dizer que a amostra de água subterrânea do poço A1 não se mostrou satisfatória, trata-se de um poço artesiano, localizado próximo as margens da rodovia RJ 220, município de Natividade, e o mesmo apresentou uma concentração do íon $\mathrm{NO}_{3}{ }^{-}$acima do permitido pela Resolução ${ }^{\circ} 357$ do CONAMA.

Portanto, com exceção do poço A1, todos os resultados obtidos pelas análises dos poços A2, A3, A4 e A5 atenderam aos parâmetros permitido pela legislação vigente. Contudo ressaltase que se o objetivo for a liberação ou não para o consumo humano faz-se necessário a realização de novas análises com outros parâmetros que não foram utilizados nesta pesquisa. Finalmente, ressalta-se também, que para uma análise superficial dos possíveis contaminantes presentes ou ausentes em amostras de água subterrâneas a metodologia aplicada nessa pesquisa se mostrou satisfatória.

\section{Referências}

ALLÉGRE, C.J., et al. Sr-Nd-Pb isotopes systematics in Amazon and Congo river systems: Constrain about erosion processes. Chemical Geology, 131: 93-112. 1996.

ALMEIDA, M. Geografia Global 2. São Paulo: Escala Educacional. 2010. 
ANA. AGÊNCIA NACIONAL DE ÁGUAS. Parâmetros de Qualidade de Água. Superintendência de Gestão da Rede Hidrometeorológica - SCH. Brasília, DF. Disponível em:<http://capacitacao.ana.gov.br/Lists/Cursos_Anexos/Attachments/32/Par\%C3\%A2metros.pd f> Acesso em 14 de Setembro de 2016.

ANA. AGÊNCIA NACIONAL DE ÁGUAS. Águas Subterrâneas. 2009. Disponível em:<http://www.uniagua.org.br/public_html/website/estudo_aguas_subterraneas.pdf $>$. Acesso rm 18 de Setembro de 2016.

ARAÚJO, M. C. de; SANTOS, F. M. da S.; OLIVEIRA, M. B. M. de. Análise da qualidade da água do riacho Cavouco - UFPE. Recife, PE. 2012/2013. Disponível em <http://www.unicap.br/encontrodasaguas/wp-content/uploads/2013/07/Marlyeta-Chagas-deAraujo-ufpe-Trabalho_2073002545.pdf> Acesso em 16 de setembro de 2016

BAIRD, C.; CANN, M. Química Ambiental. 4. ed. Porto Alegre: Bookman, 2011. Acesso em 13 de Setembro de 2016.

BARBOSA, C. F. Hidrogeoquímica e a contaminação por nitrato em água subterrânea no bairro Piranema, Seropédica - RJ. 2005. Dissertação (Mestrado) - Universidade Estadual de Campinas, Campinas. Disponível em: <http:// www.bibliotecadigital.unicamp.br > Acesso em 16 Setembro de 2016.

BARRETO, P. R.; GARCIA,C. A. B. Caracterização da qualidade da água do açude BuriFrei Paulo/SE. Scientia Plena, v. 6, n. 9, pp. 01-21, 2010. Acesso em 8 de Setembro de 2016.

BRASIL. Ministério da Saúde. Secretaria de Vigilância em Saúde Coordenação Geral de Vigilância em Saúde Ambiental. Programa Nacional de Vigilância Ambiental em Saúde Relacionada à Qualidade da Água para Consumo Humano. Brasília, 2004. 43p. Acesso em 9 de Outubro de 2016.

BRASIL. Portaria $\mathbf{n}^{0}$ 2914, de 12 de Dezembro de 2011. Dispõe sobre os procedimentos de controle e de vigilância da qualidade da água para consumo humano e seu padrão de potabilidade. Brasília: Editora do Ministério da Saúde, 2011. 34p. Acesso em 9 de Outubro de 2016.

BRASIL. Resolução CONAMA n ${ }^{0}$ 357. Dispõe sobre a classificação dos corpos de água e diretrizes ambientais para o seu enquadramento, bem como estabelece as condições e padrões de lançamento de efluentes, e dá outras providências. Publicada no DOU nº 053, de 18/03/2005, p. 58-63. Disponível em:<www.mma.conama.gov.br/conama> Acesso em 10 de Outubro de 2016.

BRASIL. Resolução CONAMA, n 396. Dispõe sobre a classificação e diretrizes ambientais para o enquadramento das águas subterrâneas e dá outras providências. Publicada no DOU n ${ }^{\circ} 66$, de 7 de abril de 2008, Seção 1, pp. 64-68. Disponível em: < www.mma.conama.gov.br/conama > Acesso em 10 de Outubro de 2016.

CAMPOS, T. DE S.; ROHLFS, D.B. Avaliação dos valores de nitrato em águas subterrâneas e sua correlação com atividades antrópicas no município de Águas Lindas de Goiás. Goiânia. PUC, 2011. Acesso em 12 de Outubro de 2016.

Center Poços < http://www.sacrahome.com.br/centerpocos/aguas-subterraneas>. Acesso em 20 de Setembro de 2016. 
COLVARA, J.G.; LIMA, A.S.; SILVA, W.P. Avaliação da contaminação de água subterrânea em poços artesianos no sul do Rio Grande do Sul. Braz. J. Foode Technol., II SSA, janeiro, 2009.

CORCÓVIA, J. A.; CELLIGOI, A. Avaliação preliminar da qualidade da água subterrânea no município de Ibiporã-PR. Revista de estudos ambientais, v. 14, n. 2esp, p. 39-48, 2012.

FELTRE, R. Físico-química. 6. Ed., v.2, p.228. São Paulo: Moderna, 2004.

FUNASA - FUNDAÇÃO NACIONAL DE SAÚDE. Manual de Controle da Qualidade da Água para Técnicos que Trabalham em ETAS. 2014. 1. ed, 112 p. Brasília, DF.

GOMES, A. S.; CLAVICO, E. Propriedades físico-químicas da água. Departamento de Biologia Marinha. UFF, 2005. Disponível em 〈http://www.uff.br/ecosed/propriedadesH2O.pdf> Acesso em 14 de Setembro de 2016.

GUIMARÃES, P. B. V. RIBEIRO, M. M. R. Águas subterrâneas: aspectos compartilhados da gestão de recursos hídricos na legislação brasileira. In: XV Congresso Brasileiro de Águas Subterrâneas, Natal. 2008.

HIRATA, R. Recursos hídricos. In: Decifrando a terra. Wilson Teixeira et al. (org.) 2. Reimpressão, São Paulo: Oficinas de textos, 2003.

LOUGON, M. S. et al. Caracterização dos sólidos totais, fixos e voláteis nas águas residuais geradas pela lavagem dos frutos do cafeeiro. UFES - Departamento Engenharia Florestal, Programa de Pós-Graduação em Ciências Florestais. Jerônimo Monteiro, ES. 2009 a 2010.

MARQUES, M. N., et al. Avaliação do impacto da agricultura em áreas de proteção ambiental, pertencentes à bacia hidrográfica do rio Ribeira de Iguape, São Paulo. Quim. Nova, v. 30, n. 5, p.1171-1178, 2007.

MOREIRA, D. A., et al. Qualidade das águas de minas no perímetro urbano do município de Ubá-MG. Multi-Science Journal, 2015.

NAMES, P. L. M. F. Qualidade das águas subterrâneas de poços tipo cacimba: um estudo de caso da comunidade nascença - município de São Sebastião - AL. III Congresso Brasileiro de Gestão Ambiental, Goiânia, 2012.

NASCIMENTO, S. A. M., et al. Hidrogeoquímica e índice de saturação dos minerais no sistema aquífero do Alto Cristalino de Salvador, Bahia. Revista Brasileira de Geociências, v. 39, n. 2, 2009.

OLIVEIRA, L. I. \& LOUREIRO, C. O. Contaminação de aquíferos por combustíveis orgânicos em Belo Horizonte: Avaliação preliminar. In: $X$ Congresso Brasileiro de Águas Subterrâneas. 21 de Abril 2000 <http://www.abas.org/congressos/x1998/art61.html>. Acesso em 18 de Setembro de 2016.

OLIVEIRA, L. I. \& LOUREIRO, C. O., 1998, Contaminação de aquíferos por combustíveis orgânicos em Belo Horizonte: Avaliação preliminar. In: X Congresso Brasileiro de Águas 
Subterrâneas. 21 de Abril 2000 <http://www.abas.org/congressos/x1998/art61.html> Acesso em 16 de Setembro de 2016.

PALUDO, D. Qualidade da Água nos poços artesianos do Município de Santa Clara do Sul. UNIVATES, Lajeado. 2010.

QUEIROZ, L.F., et al. Avaliação qualitativa dos poços artesianos do setor oeste, Goiânia-GO. UCG, v. 2, 2004.

REBOUÇAS, A. C. Águas Doces do Brasil, Ed. Escrituras, São Paulo, 2003.

RIBEIRO, Maria Claudia Martins. Nova Portaria de Potabilidade de Água: Busca de consenso para viabilizar a melhoria da qualidade de água potável distribuída no Brasil. Revista DAE, Diretoria de Tecnologia, Empreendimentos e Meio Ambiente - T. Superintendência de Pesquisa, Desenvolvimento e Inovação Tecnológica - Pinheiros, São Paulo - SP - Brasil. n. 189, ma/ag, 2012.

SAIDELLES, A. P. F., et al. Indicativo sobre possíveis problemas de potabilidade em poços no município de Alegrete-RS. Ciência e Natura, Santa Maria, v. 36 n. 3 set - dez. 2014.

SANTOS, Aline Gomes da Silva. Qualidade da Água Subterrânea utilizada para consumo humano no entorno do cemitério do campos Santo em Salvador/BA. Dissertação (Mestrado em Saúde, Ambiente e Trabalho) - Universidade Federal da Bahia, Faculdade de Medicina da Bahia, Salvador, 2014.

SCALIZE, P.S., et al. Avaliação da qualidade da água para abastecimento no assentamento de reforma agrária Canudos, Estado de Goiás. Rev. Ambient. Água, v.9, n.4, Taubaté, out$\operatorname{dez}, 2014$.

SEMARH. Secretaria do Meio Ambiente e dos Recursos Hídricos. Estado do Alagoas. <www.semarh.al.gov.br>. Acesso em 2 de Outubro de 2016.

SILVA, L. C. M.; BROTTO, M. E. Nitrato em Água: Ocorrência e Consequências. Faculdade Oswaldo Cruz. São Paulo - SP. 2014. Acesso em 24 de Setembro de 2016.

SPIRO, T. G.; STIGLIANI, W. M. Química ambiental. 2. ed. São Paulo: Pearson Prentice Hall, 2009. Acesso em 18 de Outubro de 2016.

TRENTIN, P.S.; BOSTELMANN, E. Programa Interlaboratorial. Para Sólidos Totais dissolvidos e em suspensão em amostras de águas. Dezembro, 2010.

UFA - Universidade Federal de Alagoas; UFSC - Universidade Federal de Santa Catarina. Princípios de hidrologia ambiental. Curso de aperfeiçoamento em gestão de recursos hídricos. [2009?].

ZOBY, José Luiz Gomes; MATOS, Bolivar. Águas subterrâneas no Brasil e sua inserção na Política Nacional de Recursos Hídricos. Águas Subterrâneas, n. 1, 2002. 